\title{
A CLINICAL STUDY OF DISPLACED CLAVICLE FRACTURES TREATED WITH ANATOMICALLY PRECONTOURED LOCKING COMPRESSION PLATE
}

\author{
Venkatesh M. Mulimani ${ }^{1}$, Manikya Ramesh², Chavan Pramod Babu ${ }^{3}$, Akash Hosthota $^{4}$
}

${ }^{1}$ Associate Professor, Department of Orthopaedics, Karnataka Institute of Medical Sciences.

${ }^{2}$ Senior Resident, Department of Orthopaedics, Karnataka Institute of Medical Sciences.

$3 J u n i o r$ Resident, Department of Orthopaedics, Karnataka Institute of Medical Sciences.

4Junior Resident, Department of Orthopaedics, Karnataka Institute of Medical Sciences.

\begin{abstract}
BACKGROUND

Clavicle is the bony structure that links shoulder girdle to thorax and is ' $\mathrm{S}$ ' shaped bone. Clavicle fracture is a common traumatic injury around shoulder girdle due to their subcutaneous position. It has been managed non-operatively in many cases. This study was undertaken to study the outcome of surgical management in displaced or comminuted clavicular fractures with precontoured Locking Compression Plates.
\end{abstract}

\section{MATERIALS AND METHODS}

Twenty adult patients with clavicular fractures treated surgically between November 2011 and October 2013 were included for this study and treated surgically with precontoured Locking Compression Plates.

\section{RESULTS}

Among 20 patients with middle third clavicle fracture treated with precontoured locking plate, 18 fractures united at an average of 9.3 weeks; 2 patients had delayed union, 2 patients had plate loosening and 3 patients had plate prominence. The functional outcome according to Constant and Murley score after fracture union were excellent in 16 patients, good in 3 patients and fair in 1 patient.

\section{CONCLUSION}

This study shows rigid fixation with precontoured Locking Compression Plates for fresh displaced or comminuted middle third clavicle fracture, we can archive immediate pain relief and avoid the complications like shoulder stiffness and non-union.

\section{KEYWORDS}

Clavicle-Injuries, Fractures-Fixation, Internal-Methods, Fractures-Surgery, Internal-Fixator.

HOW TO CITE THIS ARTICLE: Mulimani VM, Ramesh M, Babu CP, et al. A clinical study of displaced clavicle fractures treated with anatomically precontoured locking compression plate. J. Evolution Med. Dent. Sci. 2016;5(83):6218-6222, D0I: 10.14260/jemds/2016/1404

\section{BACKGROUND}

Clavicle is the bony structure that links shoulder girdle to thorax and is ' $\mathrm{S}$ ' shaped bone. Clavicle fracture is a common traumatic injury around shoulder girdle due to their subcutaneous position. Fracture of the clavicle accounts for approximately 5 to $10 \%$ of all fractures and up to $44 \%$ of injuries to the shoulder girdle. Allman et al have classified clavicle fractures into three groups. ${ }^{1}$

- Group I: Middle third

- Group II: Lateral third

- $\quad$ Group III: Medial third.2

Mid-clavicular fractures is one of the most common injuries of the skeleton representing $3 \%$ to $5 \%$ of all fractures and $45 \%$ of shoulder injuries.

Financial or Other, Competing Interest: None.

Submission 08-09-2016, Peer Review 05-10-2016,

Acceptance 11-10-2016, Published 17-10-2016.

Corresponding Author:

Dr. Akash Hosthota,

Department of Orthopaedics,

202, Kims Hospital,

Vidyanagar,

Hubli-580022, Karnataka.

E-mail:dr.akashhosthota@gmail.com

DOI: $10.14260 /$ jemds $/ 2016 / 1404$

\section{(c) $(1)(-$}

The annual incidence of mid-clavicular fractures is 64 per 100,000 population. ${ }^{3}$ Breaks of the shaft form $70 \%$ to $80 \%$ of all clavicular fractures; lateral fractures contribute $15 \%$ to $30 \%$, and medial fractures at $3 \%$ are relatively rare. Open clavicular fractures is an absolute rarity found only in $0.1 \%$ to $1 \%$ of cases. The rate of mid-clavicular fractures is more than twice as high in men as in women. The peak incidence occurs in the third decade of life. 4

Midshaft clavicular fractures, which are undisplaced and minimally displaced have traditionally been treated conservatively. Surgical treatment of acute mid-shaft clavicle fractures was not favoured due to relatively frequent and serious complications. However, the prevalence of non-union or malunion in displaced mid-shaft clavicle fractures after conservative treatment is higher than previously presumed and fixation methods have evolved. ${ }^{5}$ Surgery is accepted more and more as primary treatment for displaced mid-shaft clavicle fractures, mainly because the results of operative treatment is superior both clinically and functionally. ${ }^{6}$

There are various methods of treating clavicle mid-shaft fractures such as intramedullary K-wires or Steinmann pins fixation and plate fixation. In particular, locking compression plate fixation can help obtain firm anatomical reduction in severe displaced or comminuted fractures. ${ }^{7}$

There are various plates including Sherman plates, dynamic compression plates and semitubular plates. Among 
them a reconstruction plate or a precontoured locking compression plate are the most preferred. We have taken up this study to gain a deeper understanding of the outcome and problems associated with this procedure to evaluate the functional outcome after fixation of displaced clavicular fractures with locking compression plates.

\section{METHODOLOGY}

The present study was carried out from November 2011 to October 2013 at Orthopaedics Department in Karnataka Institute of Medical Sciences, Hubli. During this period, 20 patients of displaced clavicular fractures were treated surgically.

\section{Inclusion Criteria}

1. Age $>18$ years.

2. Closed fracture.

3. Robinson Classification 2B1 and 2B2 (Displaced fractures). ${ }^{8}$

4. No medical contradictions to general anaesthesia.

\section{Exclusion Criteria}

1. Age $<18$ years.

2. Open fractures.

3. Fracture in proximal or distal third of clavicle.

4. Pathological fractures.

5. Undisplaced fractures.

6. Associated head injury.

7. Associated with neurovascular injury.

8. Established non-union from previous fracture.

9. Associated acromioclavicular joint dislocation.

Plain radiograph of clavicle with shoulder in anteroposterior view was taken to assess the site of fracture and the fracture type (Displacement and comminution). The fractures were classified according to Robinson's classification. The affected upper limb was immobilised in an arm pouch.

Patient was induced with general anaesthesia positioned in beach chair position; 7-8 cm of incision was taken over the clavicle after stretching the skin proximally, centring over the fracture; subcutaneous tissue, fascia and platysma were dissected; fracture was exposed and muscles were elevated from the periosteum, fracture reduced and stainless steel precontoured anatomical plates were used to fix the fracture with min 3 no, $3.5 \mathrm{~mm}$ cortical screws on either side. Wound was closed in layers, sterile dressing applied and limb immobilised with arm pouch.

The operated upper limb was immobilised in an arm pouch. Check x-rays were taken to study the alignment of fracture fragments. The wound was inspected at $3^{\text {rd }}$ or $4^{\text {th }}$ postoperative day. Suture removal was done on $10^{\text {th }}$ postoperative day. Patients were discharged with the arm pouch. Rehabilitation of the affected arm was started at the end of 2 weeks. Gentle pendulum exercises to the shoulder in the arm pouch were allowed. At 4 to 6 weeks gentle active range of motion of the shoulder was allowed, but abduction is limited to 80 degrees. At 6 to 8 weeks, active range of motion in all planes were allowed.

Regular followup for every 4 weeks was done. Local examination of the affected clavicle for tenderness, instability, deformity and shoulder movements were assessed. X-rays were taken at each followup visits to know about progressive fracture union and implant position. Rehabilitation of the affected extremity was done according to the stage of fracture union and time duration from day of surgery. Patients were followed up till radiological union. The functional outcome were assessed by Constant and Murley score. ${ }^{9}$

\section{RESULTS}

The present study consists of 20 patients of fresh fracture of clavicle, which were treated surgically by stainless steel locking plate and screws for middle third clavicle fracture between November 2011 and October 2013 at KIMS Hospital, Hubli. All patients were available for followup and they were followed every 6 weeks. Results were analysed both clinically and radiologically. Plain radiograph of clavicle with shoulder in anteroposterior view to assess the site of fracture and the type of fracture (Like displacement, angulation, comminution).

In this study, Robinson classification was followed. Type 2 middle third fracture type-2 B1 (Displaced with simple or single butterfly fragment) occurred in 16 patients (80\%) and type-2 B2 (Displaced with comminuted or segmental) fracture occurred in 4 patients (20\%). The fracture was considered to be united when clinically there was no tenderness; radiologically the fracture line was not visible and full unprotected function of the limb was possible. In this study, 18 patients $(90 \%)$ united at the end of 12 weeks. In 2 patients, $(10 \%)$ delayed union occurred which united at the end of 16 weeks each. We advised the patient for removal of the plate at the end of 1 year; 2 patients had turned up for implant removal. So implant removal was done in these 2 patients till the end of this study. The functional outcome is assessed by Constant and Murley score. In this study 16 patients $(80 \%)$ had excellent functional outcome, good functional outcome occurred in 3 patients (15\%) and fair in 1 patient (5\%).

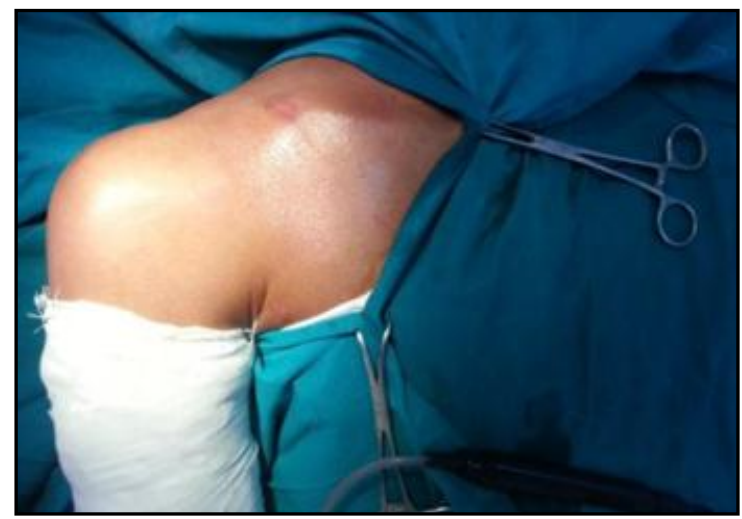

Fig. 1: Position of the Patient (Beach Chair)

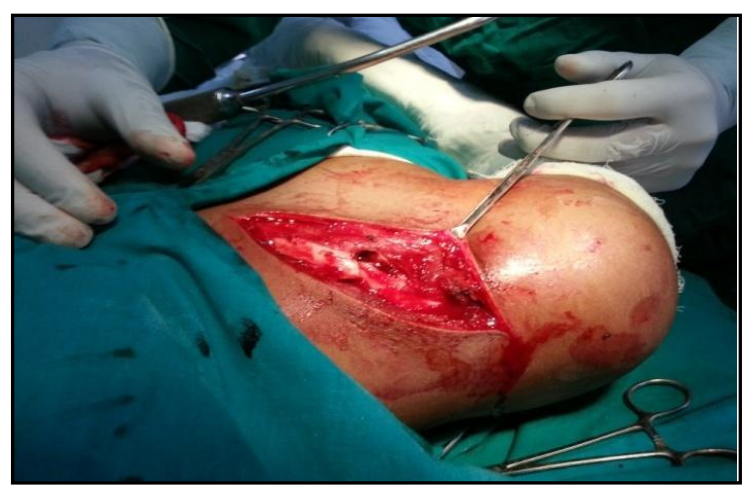

Fig. 2: Incision and Exposure 


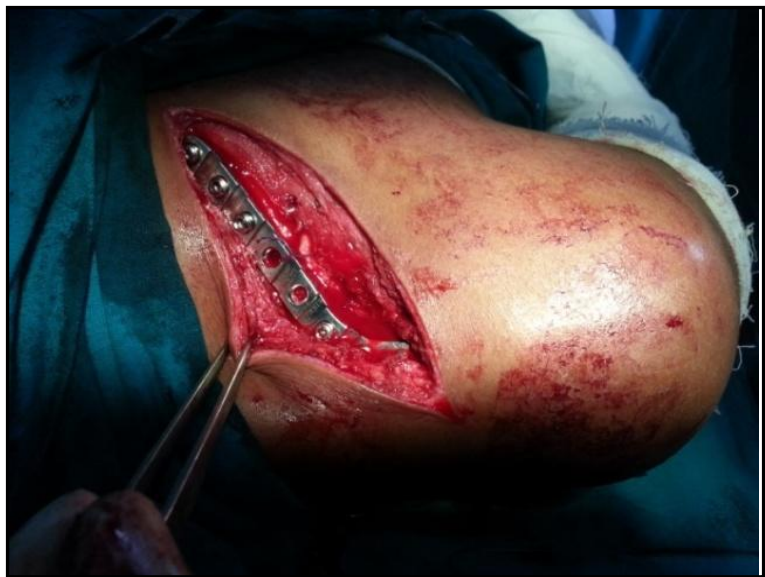

Fig. 3: Plate Placement and Reduction

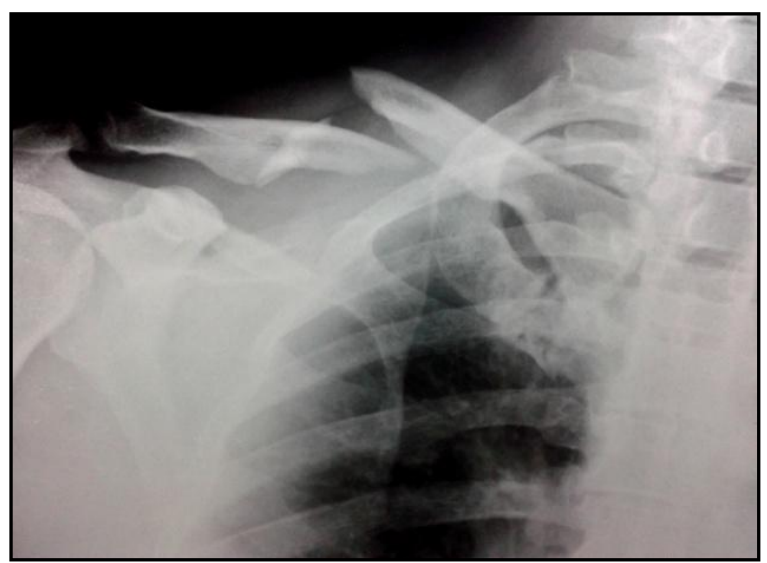

Fig. 4: Pre-Op Radiograph

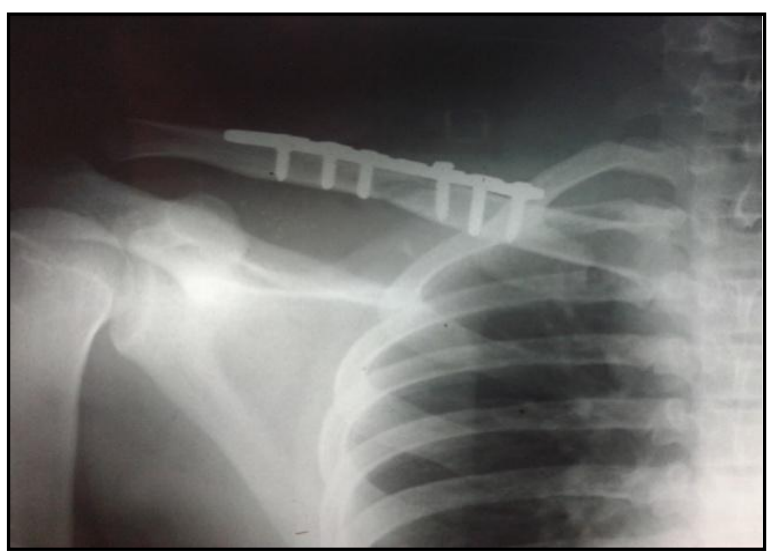

Fig. 5: Post-Op Radiograph

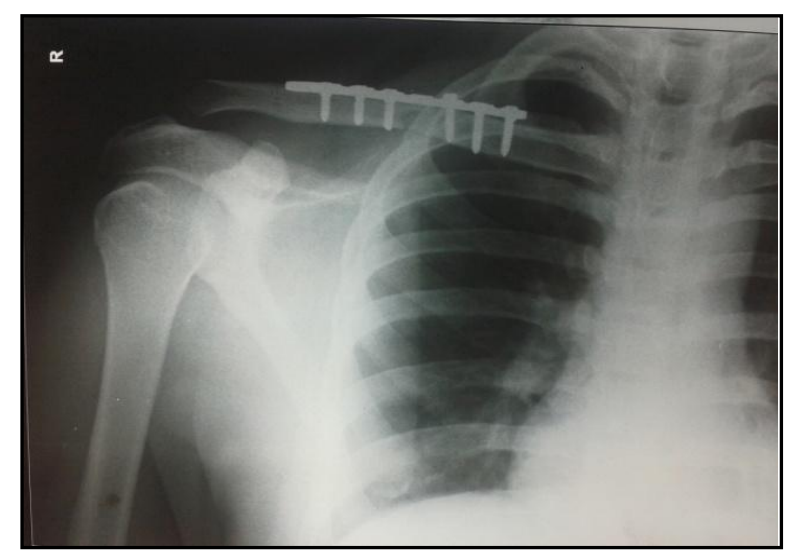

Fig. 6: Followup Radiograph

\section{DISCUSSION}

In a study conducted to analyse the results of conservative treatment by Hill et al ${ }^{10}$ in 1997, Nordqvist et al ${ }^{11}$ in 1998 and Robinson et al ${ }^{12}$ in 2004 found poor results following conservative treatment of displaced middle third clavicle fracture. So there are specific indications like displacement with or without comminuted middle third clavicle fracture (Robinson Type-2 B1, 2 B2) for which operative treatment is needed. Our study was compared with similar studies published till date.

The present study of patients with middle third clavicle fractures is compared with Bostman et al11 study, which treated only middle third clavicle fractures; in this totally 103 patients were treated by early open reduction and internal fixation with plate and screws. It was also compared with Cho et al ${ }^{12}$ study, where 41 patients with a clavicle mid-shaft fracture were treated by internal fixation with a reconstruction plate (19 patients) or reconstruction LCP (22 patients). It was also compared with VanBeek et al ${ }^{13}$ study, where they compared outcomes after precontoured and non-contoured superior plating of acute displaced mid-shaft clavicle fractures. In this they retrospectively reviewed 52 patients with 52 acute, displaced, mid-shaft clavicle fractures treated with either noncontoured or precontoured superior clavicle plate fixation. Non-contoured (14) in which DCP (4), LCP (2), LCDCP (4), reconstruction plate (4) and precontoured (28), locking clavicle plate (28). Fourteen patients with non-contoured plates and 28 with precontoured plates were available for followup at a minimum of 1 year postoperatively.

In this study the patients with middle third clavicle fracture, the mechanism of injury was due to fall on the shoulder from vehicle in 9 patients (45\%), road traffic accident in 5 patients (25\%), simple fall on the shoulder in 4 patients (20\%), fall on outstretched hand in 2 patients (10\%). In Bostman et al ${ }^{11}$ study, the mechanism of injury was due to fall from the two wheeler in 38 patients (36.8\%), slipping and fall in 24 patients $(23.30 \%)$, motor vehicle accident in 19 patients $(18.45 \%)$ and sports injury in 22 patients $(21.36 \%)$. In Cho et $\mathrm{al}^{12}$ study, in reconstruction plate group there were 13 patients who sustained road traffic accident, 3 patients with slip down, 1 patient with sports injury, 1 patient with fall down and 1 patient with miscellaneous mode of injury. In locking compression plate group, there were 7 patients with road traffic accident, 3 patients with slip down, 1 patient with fall down and 1 patient with miscellaneous mode of injury. In VanBeek et al ${ }^{13}$ study, the most common mechanism of injury was fall in 19 patients, sports related injuries in 17 patients and motor vehicle trauma in 6 patients. This shows direct injury to the shoulder is the common cause of this fracture.

In this study, middle third clavicle fracture commonly occurred between the age group of 19 to 29 years in 7 patients (35\%). The youngest patient's age was 19 years and oldest patient's age was 58 years. The average patient's age was 35.25 years. In Bostman et al ${ }^{11}$ study, patient's average age was 33.4 years and the youngest patient's age was 19 years and oldest patient's age was 62 years. In Cho et al ${ }^{12}$ study, in reconstruction plate group the mean age was 45 years (range 22-70 years) and that of locking compression plate group was 46 years (range 19-69 years). In VanBeek et al ${ }^{13}$ study, average age of patients in precontoured plating group was 36 years (range 13-68 years) and in non-contoured plating group was 28.9 years (range $19-50$ years). 
From this, we can infer that clavicle mid-shaft fractures occur in young patients.

In this study majority of patients were male, 19 patients (95\%) and 1 female patient (5\%). In Bostman et al ${ }^{11}$ study also commonly males were affected, 76 patients $(73.79 \%)$ compared to 27 female patients (26.21\%). In Cho et al ${ }^{12}$ study, the reconstruction plate group 12 male and 7 female patients and in locking compression plate group it was 17 male and 5 female patients. In VanBeek et al $^{13}$ study in precontoured plate group, 22 male and 6 female patients and in non-contoured plate group it was 10 male and 4 female patients. This shows male predominance in mid-shaft clavicle fracture.

In this present study, Robinson Type- 2 B1 (Displaced with simple or butterfly fragment) were common and there were 16 patients (80\%), Type-2 B2 (Displaced with comminution) occurred in 4 patients $(20 \%)$. In Bostman et al ${ }^{11}$ study also Robinson Type-2 B1 was common in 81 patients (78.64\%). Robinson Type-2 B2 occurred only in 22 patients (21.36\%). In Cho et al ${ }^{12}$ study, in reconstruction plate group there were 7 patients with Robinson Type-2 B1 and 12 patients with Robinson Type-2 B2 and that of locking compression plate group had 9 patients with Robinson Type-2 B1 and 13 patients with Robinson Type-2 B2 fractures. In VanBeek et al ${ }^{13}$ study, 20 patients had Robinson Type- 2 B1 and 25 patients had Robinson Type-2 B2 fractures.

In our study 7 hole plates were used in 11 patients (55\%), 4 patients (20\%) with 6 hole plates and 5 patients (25\%) with 8 hole plates depending upon type of fracture. In Bostman et al ${ }^{11}$ study, plate length was above 6 holes to place at least three screws in each fragment. Plate also depends upon the amount of comminution.

In our study majority of the middle third clavicle fractures united between 8 to 12 weeks, i.e. 18 patients (90\%). In 2 patients (10\%), delayed union occurred as there was a displaced butterfly fragment which united with the main fragment at the end of 16 weeks. There were no non-union. Lazarus MD stated radiological union occurred approximately between 6 to 12 weeks. In Cho et al ${ }^{12}$ study, bony union for reconstruction plate was 14.6 weeks and that for locking compression plate was 13.2 weeks.

Plate prominence occurred in 3 patients (15\%); 1 patient underwent implant removal for the same after union of the fracture. In VanBeek et $\mathrm{al}^{13}$ study, plate prominence was reported postoperatively in 9 of 14 patients $(64.3 \%)$ of the non-contoured group and 9 of 28 patients (32.1\%) of the precontoured group; 3 of 14 (21.4\%) of the non-contoured patients and 3 of $28(10.7 \%)$ of the precontoured patients ultimately underwent elective removal of hardware for plate prominence.

Delayed union occurred in 2 patients $(10 \%)$ due to a large butterfly fragment, which went on to unite by 16 weeks. In Bostman et al ${ }^{11}$ study, delayed union occurred in 3 patients (2.91\%). In VanBeek et al ${ }^{13}$ study, non-union occurred in 1 patient with revision surgery with bone grafting was done.

The total complication in this study was $20 \%$ excluding skin related minor complications. The total complication rate in Bostman et al ${ }^{11}$ study was $23 \%$. The total complication rate in VanBeek et $\mathrm{al}^{13}$ study was $64.3 \%$ in non-contoured group and $39.3 \%$ in precontoured group.

The functional outcome according to Constant Murley Scoring ${ }^{9}$ in this study of total 20 patients of middle third clavicle fracture fixed with locking compression plate and screws showed excellent results in 16 patients (80\%) and good functional outcome in 3 patients (15\%). Fair functional outcome in 1 patient (5\%).

In this study, precontoured locking plates were used as it is contoured to the shape of the clavicle. It is necessary to put the plate superiorly and at least three screws to be applied medially and three screws laterally. The advantages of locking plates include strong fixation due to locking between the screw and plate, blood supply preservation due to minimal contact between plate and cortical bone, reduced risk of injury to subclavian vessels and brachial plexus as tip of the screw need not reach the opposite cortex, periosteal stripping is minimised to promote rapid union and contouring of plate not needed and hence surgical time is reduced and post-operative plate prominence and hardware related problems are also reduced.

The advantage of rigid internal fixation and early mobilisation of fresh displaced clavicle fracture is that it (displaced comminuted middle third and displaced lateral third clavicle fracture) gives immediate pain relief and prevents the development of shoulder stiffness and non-union.

\section{CONCLUSION}

Undisplaced clavicle fractures are treated conservatively but the indications for which operative treatment are comminuted, displaced middle third clavicle fractures and displaced lateral third clavicle fracture. Among the internal fixation methods intramedullary fixation with K-wire or Steinmann pin do not control rotation and have low resistance to torque, carry risk of pin loosening and infection, so they require longer period of immobilisation till union.

Open reduction and internal fixation with plates, such as Sherman plates, dynamic compression plates and semitubular plates can be effective in obtaining anatomical reduction, applying direct compression to fracture site and producing resistance to torque. However, it is disadvantageous in achieving firm fixation because it is difficult to hold plates to the clavicle in severely comminuted fracture cases. In contrast, reconstruction plates can be manipulated to fit the contour of the clavicle and fracture pattern to obtain firm fixation, are lighter and thinner than dynamic compression plates and are durable to multidirectional mechanical stress imposed on the fracture site.

This study has some limitations. The conclusions drawn from this analysis cannot be generalised because of the smaller number of cases. In conclusion, bony union could be achieved with precontoured locking clavicle plate by reducing the complication rates in mid-shaft comminuted displaced clavicle fractures and functional outcome were satisfactory.

\section{REFERENCES}

1. Bucholz RW, Heckman JD. Charles court-brown. Rockwood and green's fractures in children 2006;6(22):896-934.

2. Craig EV, Basamania CJ, Rockwood CA. Fractures of the clavicle. $3^{\text {rd }}$ edn. In: Rockwood CA, Matsen FA, Wirth MA, et al. Chapter-11, The shoulder. Philadelphia: Saunders, 2004:455-519.

3. Allman FL. Fractures and ligamentous injuries of the clavicle and its articulation. J Bone Joint Surg Am 1967;49(4):774-84.

4. Schiffer G, Faymonville C, Skouras E, et al. Midclavicular fracture: not just a trivial injury-current treatment options. Dtsch Arztebl Int 2010;107(41):711-7. 
5. Shen WJ, Liu TJ, Shen YS. Plate fixation of fresh displaced midshaft clavicle fractures. Injury 1999;30(7):497-500.

6. Hill JM, McGuire MH, Crosby LA. Closed treatment of displaced middle-third fractures of the clavicle gives poor results. J Bone Joint Surg Br 1997;79(4):537-9.

7. Modi N, Patel AD, Hallam P. Outcome of 62 clavicle fracture fixations with locked compression plate: is this the right way to go? Injury Extra 2011;42(9):118.

8. Robinson CM, Court-Brown CM, McQueen MM, et al. Estimating the risk of nonunion following nonoperative treatment of a clavicular fracture. J Bone Joint Surg Am 2004;86-A(7):1359-65.

9. Constant CR, Murley AH. A clinical method of functional assessment of the shoulder. Clinical Orthopaedics and Related Research 1987;214:160-4.
10. Nordgvist A, Petersson CJ, Redlund-Johnell I. Mid clavicular fractures in adults: end result study after conservative treatment. J Orthop Trauma 1998;12(8): 572-6.

11. Bostman O, Manninen M, Pihlajamaki H. Complications of plate fixation in fresh displaced midclavicular fractures. J Trauma 1997;43(5):778-83.

12. Cho CH, Song KS, Min BW, et al. Operative treatment of clavicle midshaft fractures: comparison between reconstruction plate and reconstruction locking compression plate. Clinics in orthopedic surgery 2010;2(3):154-9.

13. VanBeek C, Boselli KJ, Cadet ER, et al. Precontoured plating of clavicle fractures: decreased hardware-related complications? Clin Orthop Relat Res 2011;469(12): 3337-43. 